[T. Zornek, T. Monz, M. Aigner, Performance analysis of the micro gas turbine Turbec T100 with a new FLOX-combustion system for low calorific fuels, Applied Energy 159 (2015) 276-284.]

The original publication is available at www.elsevier.com

http://dx.doi.org/10.1016/j.apenergy.2015.08.075 


\section{Abstract}

This paper presents the first combustion system, which has been designed for the use of biomass derived product gases in micro gas turbines. The operating performance of the combustion system and of the micro gas turbine Turbec T100 was analyzed experimentally with synthetically mixed fuel compositions. Reliable start-up procedures and steady-state operation were observed. The Turbec T100 reached an electrical power output of 50 to $100 \mathrm{~kW}_{e l}$ with a lower heating value of $5.0 \mathrm{MJ} / \mathrm{kg}$. Compared to natural gas, the electrical power output was noticeably higher at constant turbine speeds. Therefore, operation was limited by the power electronic at low speeds, while a second limitation was compressor surging at high speeds. To avoid surging, the turbine outlet temperature had to be reduced at turbine speeds between $64,400 \mathrm{rpm}$ and its maximum of 70,000 rpm. The pressure losses across the FLOX-combustion chamber remained below 4\%, which corresponds to a reduction of $30 \%$ compared to the Turbec combustion chamber fired with natural gas. Low pollutant emissions, i.e. $\mathrm{CO}<30 \mathrm{ppm}, \mathrm{NO}_{x}<6 \mathrm{ppm}$ and unburnt hydrocarbons $<1 \mathrm{ppm}$, were obtained over the whole operating range. Further optimization potential of the Turbec T100 was analyzed numerically. Neglecting compressor surging and the limitations of the power electronic, the numerical simulations predicted a maximum power output of $137 \mathrm{~kW}_{e l}$. The ability of the micro gas turbine to run with low calorific fuels is demonstrated and optimization potential is specified.

\title{
Performance analysis of the micro gas turbine Turbec T100 with a new FLOX-combustion system for low calorific fuels
}

\author{
German Aerospace Center, Institute of Combustion Technology, Pfaffenwaldring 38-40, 70569 Stuttgart \\ T.Zornek*, T.Monz, M.Aigner
}


Highlights

- A new FLOX-combustion system has been successfully tested in a micro gas turbine

- The operating performance of the Turbec T100 with LCV fuels was characterized

- Reliable start-up and steady-state operation from 50 to $100 \mathrm{~kW}_{e l}$ was observed

- Low emissions over the whole operating range: $\mathrm{CO}<30 \mathrm{ppm}, \mathrm{NO}_{x}<6 \mathrm{ppm}, \mathrm{UHCs}<1 \mathrm{ppm}$

- The pressure drop across the combustion system was below $4 \%$ 


\section{Nomenclature}

A

c

Lst

lst

$\dot{m}$

$\dot{m}_{C}$

$\mathrm{N}$

$N_{C}$

$\mathrm{p}$

$\Delta p^{t}$

$R_{i}$

$\mathrm{T}$

$x_{i}$

$\lambda$

$\rho$

Abbreviations

CHP

CIT

FLOX

LCV

LHV

MGT

NG

$\mathrm{PG}$

TOT

$\mathrm{UHC}$ cross-section

velocity

stoichiometric air-to-fuel ratio

oxygen demand for complete oxidation

mass flow rate

corrected mass flow rate

rotational speed

corrected rotational speed

static pressure

total pressure

total pressure losses

specific gas constant

temperature

molar fraction

air number

density

Combined heat and power

Combustor inlet temperature

Flameless oxidation

Low calorific value

Lower heating value

Micro gas turbine

Natural gas

Product gas

Turbine outlet temperature

Unburnt hydro carbons 


\section{Introduction}

For decentralized combined heat and power (CHP) production, micro gas turbines (MGT) constitute a promising technology [1]. The stationary combustion of MGTs enables low pollutant emissions without exhaust gas aftertreatment and it facilitates firing of alternative fuels. As MGTs are considered to be fuelflexible, there is a growing interest to use them in combination with biomass derived fuels [2]. For instance, using product gases from biomass gasification in efficient MGT-CHP plants offers a reduction of $\mathrm{CO}_{2}$ emissions and saves fossil resources. However, commercially available MGTs are designed for conventional fuels such as natural gas or diesel, which have a higher lower heating value (LHV). If fuels with lower LHVs are used, the fuel mass flow rate increases respectively. In case of a product gas with a LHV of $5.0 \mathrm{MJ} / \mathrm{kg}$ the fuel mass flow rate increases almost by the factor of ten compared to natural gas. Usually the fuel mass flow rate is limited by the size of the fuel valves, the flow cross-sections and the fuel pressure. Enlarging the fuel mass flow rate affects the impulse ratios inside the combustion chamber and as a consequence the flame stability. Furthermore, important combustion characteristics like flame speed and ignition delay time depend on the fuel composition. A completely new design of the combustion system is necessary if these characteristics are very different to the designated fuel. Nevertheless, only minor modifications of the original combustion system were conducted in all previous studies about the operating performance of MGTs with alternative fuels.

To analyze the impact of biogas on the operating performance of the $100 \mathrm{~kW}_{e l}$ MGT Turbec T100, Nikpey et al. 3] diluted natural gas with carbon dioxide at various load points. They found that $15 \% \mathrm{CO}_{2}$ (in mole fraction) could be added until flame out occured at part load with a power output of $50 \mathrm{~kW}_{e l}$. The possible amount of $\mathrm{CO}_{2}$ decreased to $10 \%$ at full load and $100 \mathrm{~kW}_{e l}$. The $\mathrm{LHV}$ in their study varied between 46 and $33 \mathrm{MJ} / \mathrm{kg}$. In this range, no significant changes in performance were observed. D'Alessandro et al. 4 analyzed the part load performance $\left(20-40 \mathrm{~kW}_{e l}\right)$ of the $80 \mathrm{~kW}_{e l}$ MGT from Elliot Energy systems with modified fuel nozzles. By diluting natural gas with nitrogen, the LHV was decreased down to $23 \mathrm{MJ} / \mathrm{kg}$. No significant effect on the electrical efficiency was found, which is in accordance with [3]. Similar results were obtained by Kataoka et al. [5], who operated the Elliot MGT at full load with digester gas featuring a $\mathrm{LHV}$ of $17.5 \mathrm{MJ} / \mathrm{kg}$. However, neither for LCV fuels with $\mathrm{LHV}$ selow $17.5 \mathrm{MJ} / \mathrm{kg}$ nor for fuels with a similar composition as product gases experimental data is available in literature. Some authors tried to predict the operating performance of MGTs for LCV fuels numerically. The simulations are based on models which are validated with experimental data obtained from natural gas operation. Prussi et al. 6 simulated the steady-state behavior of the Turbec T100 at full load for various blends of a representative 
biomass product gas and methane. The LHV ranged from $50 \mathrm{MJ} / \mathrm{kg}$ for pure methane down to less than $4 \mathrm{MJ} / \mathrm{kg}$ for pure product gas. Considering the energy for fuel compression, they received a sharp decrease of the electrical power output and the electrical efficiency for blends with a LHV less than $10 \mathrm{MJ} / \mathrm{kg}$. It is noteworthy that the operating points of the turbomachinery components remained in the stable range, even for the pure product gas. Bohn and Lepers [7] investigated the impact of the biogas composition on the full load perfomance of a $80 \mathrm{~kW}_{e l}$ MGT. Their results predict that the compressor remains inside the surge margin up to a methane content of only 15 Vol.-\%, i.e. a LHV of $3 \mathrm{MJ} / \mathrm{kg}$. As there are no further restrictions known, the last two studies suggest that the mentioned MGTs would tolerate low calorific fuels with a LHV of only 3 or $4 \mathrm{MJ} / \mathrm{kg}$.

To overcome the present limitation, the first LCV combustion system for MGTs has been developed in this work. It allowed an extensive characterization of the Turbec T100 with low calorific fuels featuring LHVs from 3.5 to $5.0 \mathrm{MJ} / \mathrm{kg}$. These synthetically mixed fuels were similar in composition to product gases from fixed-bed gasifiers. In this way, further operational limitations of the MGT were identified. While compressor surging limited operation at full load, the power electronic turned out to be a restriction at part load. Additionally, a numerical model was validated with the experimental data obtained in this work. The model was used to analyze optimization potentials of the Turbec T100 for product gas operation. Finally, this work gives the first comprehensive investigation of operating the MGT Turbec T100 with product gases from biomass gasification.

The developed combustion system was successfully implemented and tested in the Turbec T100. The design of the combustion system is based on the concept of flameless oxidation (FLOX) [8]. This technique is already applied in industrial furnaces and similar approaches are also known as MILD combustion [9], colorless distributed combustion (CDC) [10] or High Temperature Air Combustion (HiTAC) 11]. The FLOXconcept is an efficient and fuel-flexible combustion concept with low emissions of hazardous pollutants like $\mathrm{NO}_{x}$ and $\mathrm{CO}[8,9,12,16]$. It features a low risk of flashback as well as relative pressure losses across the combustor below 5\% [15]. Concerning low calorific value gases, Danon et al. [17] obtained low pollutant emissions with a prototype FLOX combustor. For gas turbine application, these combustion concepts are still at the level of prototypes, which have been tested at combustor test rigs. Only Zanger et al. [18] reported the succesful operation of a FLOX-based combustion system (designed for natural gas) in a MGT. 


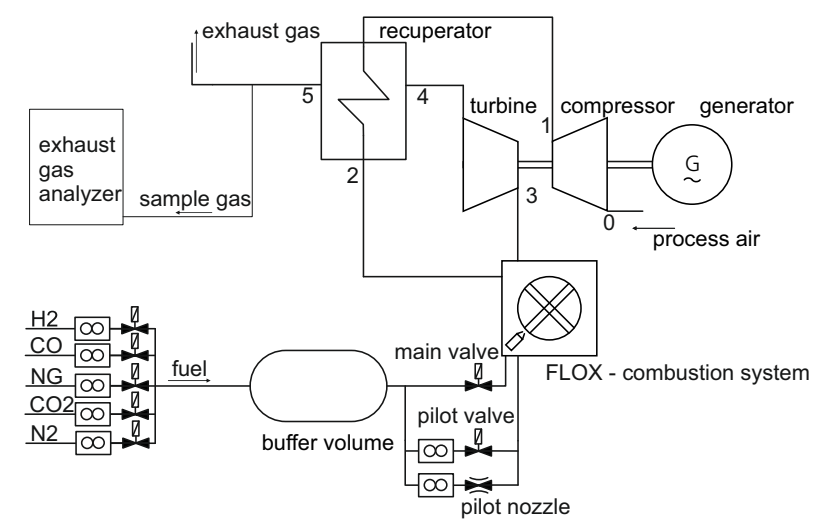

Figure 1: Schematic of the micro gas turbine test rig at DLR

\section{Experimental setup}

\subsection{Micro gas turbine test rig}

The FLOX-combustion system presented in this work has been investigated in a micro gas turbine Turbec T100PH series 3, which features a nominal electrical power output of $100 \mathrm{~kW}_{e l}$, an electrical efficiency of $30 \%$, a maximum turbine speed of $70,000 \mathrm{rpm}$ and a thermal power output of $150 \mathrm{~kW}$. A schematic of the MGT test rig at DLR is illustrated in figure 1. The MGT itself consists of a compressor, a turbine, a generator, a combustion chamber and a recuperator. The radial compressor achieves a maximum pressure ratio of 4.5. The air is heated up by compression and by the additional recuperator. The latter enhances the electrical efficiency of the MGT. The exhaust gas expands through a radial turbine, which is driving the generator and the compressor. The exhaust gas heat exchanger behind the recuperator was removed for these measurements, because the thermal power output was not investigated.

The power electronic provides the electrical power at $400 \mathrm{~V}$ and $50 \mathrm{~Hz}$. Due to the voltage in the DC-link, the operation of the power electronic is limited. There is a maximum and minimum electrical power output at a certain turbine speed. Within this range the electrical power output can be varied by changing the amount of fuel and hence the turbine outlet temperature (TOT). At higher turbine speeds, the operating range of the DC-link becomes smaller. The overall range of the power electronic is optimized to match the operating range of the natural gas fired MGT.

Within the original combustion system of the Turbec T100 the fuel is distributed into two stages, a pilot stage and a main stage. The fuel mass flow rate through the main stage is controlled in closed-loop to the TOT, while the pilot fuel mass flow rate is controlled accordingly to a preset map. This map defines the fuel mass flow rate through the pilot depending on turbine speed and TOT. The actual valve command is 
then calculated depending on the lower heating value, the fuel pressure and a valve characteristic factor. For the new FLOX-combustion system, which also containes two stages, the preset map was modified. The high fuel mass flow rate of LCV gases required bigger fuel valves, which have been installed in the test rig analog to the valve unit of the standard unit. In contrast to the Turbec valve configuration, a Coriolis mass flow controller was used for pilot fuel regulation. In this case the valve command was independent of fuel pressure. An additional adjustable nozzle provided a constant pilot fuel mass flow rate, which was used for ignition and for flame stabilization during operation. The fuel mass flow rate through the nozzle was measured by a Coriolis mass flow meter.

In order to run the MGT with a synthetic fuel composition corresponding to compositions obtained from fixed-bed concurrent gasifiers, a fuel supply system was built up. The system controlled the mass flow rates of hydrogen, carbon monoxide, natural gas, carbon dioxide and nitrogen by separate mass flow controllers. All components were mixed in a buffer volume with the required ratios. The overall fuel mass flow consumed by the MGT was obtained by the sum of the mass flow rate of the five fuel components. The main fuel mass flow rate was calculated by subtraction of the total pilot fuel (valve + nozzle) from the overall fuel mass flow. The behavior of the fuel supply system is demonstrated in figure 2, where turbine speed, fuel pressure and the percentage of each fuel component are plotted against time. Fuel composition as well as fuel pressure were stable, even during the start-up procedure. The graph proves the feasibility of the fuel system to supply the MGT with the required fuel composition. Furthermore, the graph shows that the MGT ran smoothly even during load changes.

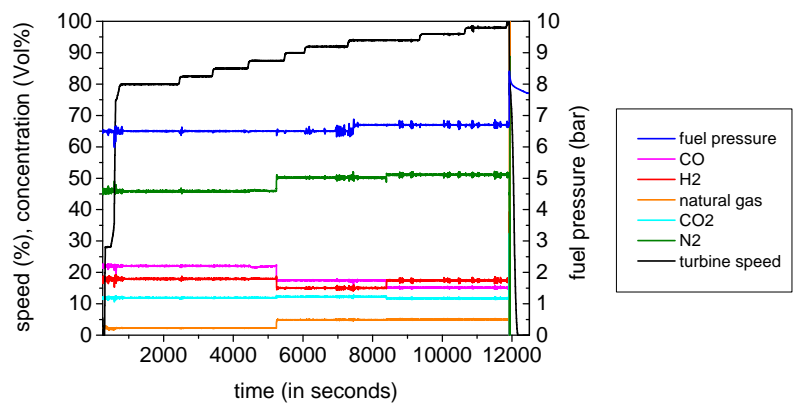

Figure 2: Fuel composition, fuel pressure and turbine speed of the turbine during operation 
Table 1: Exhaust gas analysis devices from ABB and accuracy

\begin{tabular}{llll} 
Method & Species & Range & Accuracy \\
\hline Paramagn. & $\mathrm{O}_{2}$ & $0 \ldots 25 \mathrm{Vol} \%$ & $\pm 0.125 \%$ \\
IR- & $\mathrm{CO}$ & $0 \ldots 50 \mathrm{ppm}$ & $\pm 0.5 \mathrm{ppm}$ \\
photometer & $\mathrm{CO}_{2}$ & $0 \ldots 5 \mathrm{Vol} \%$ & $\pm 0.05 \mathrm{Vol} \%$ \\
UV- & $\mathrm{NO}$ & $0 \ldots 10 \mathrm{ppm}$ & $\pm 0.1 \mathrm{ppm}$ \\
photometer & $\mathrm{NO}_{2}$ & $0 \ldots 10 \mathrm{ppm}$ & $\pm 0.1 \mathrm{ppm}$ \\
FID & $\mathrm{UHC}$ & $0 \ldots 10 \mathrm{ppm}$ & $\pm 0.1 \mathrm{ppm}$
\end{tabular}

the exhaust gas was separated by a multiple-hole probe behind the recuperator. At this point the gas outlet temperature was about 240 to $290^{\circ} \mathrm{C}$. In order to avoid condensation, the sample pipe was heated up to $180^{\circ} \mathrm{C}$. Besides the exhaust gas analysis device, the MGT test rig is equipped with various thermocouples (N- and K-type) and static as well as total pressure transducers. A more detailed description of the instrumentation of the MGT is given in [19]. Data from the exhaust gas analyzer as well as from the MGT have been recorded by a data acquisition system with a frequency of $2 \mathrm{~Hz}$. In this work, the measured data are presented as the arithmetic average over 5 minutes.

\subsection{Combustion system}

The operating conditions in the combustion chamber of the Turbec T100 vary extensively depending on the load point. During the starting period, the inlet temperature of the air and the pressure inside the combustion chamber are close to ambient conditions. The thermal load is about $10 \mathrm{~kW}_{t h}$ during ignition, whereas during stationary operation it ranges between 170 to $350 \mathrm{~kW}_{t h}$. The air is then heated up by compression and by the recuperator up to about $650^{\circ} \mathrm{C}$. The pressure inside the combustion chamber varies from 2 bars at $75 \%$ to more than 4 bars at $100 \%$ turbine speed. For these different conditions stable and complete combustion must be assured.

A common technology to achieve stable combustion over a wide operating range is to use fuel staging. Within the combustor a small fraction of fuel is injected through a pilot stage, while the rest is injected through the main stage. The pilot stage is used for ignition and stabilizes the main stage combustion during operation. It provides hot exhaust gases and combustion radicals to the main stage. In order to reduce pollutant emissions, the main stage is usually operated under lean conditions. Figure 3 shows a schematic of the employed FLOX-combustion system. The air comes from the recuperator and is split into combustion air and dilution air. The latter constitutes about $2 / 3$ of the air and enters the combustion chamber behind the combustion zone. The dilution air limits the turbine inlet temperature to a maximum of $950^{\circ} \mathrm{C}$, which is the maximum allowed inlet temperature of the turbine. The combustion air streams along the liner to 
the combustor, where it turns around and is split into main stage and pilot stage.

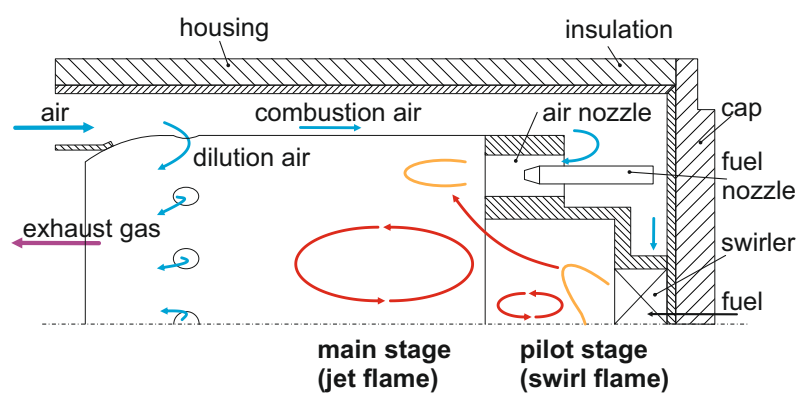

Figure 3: Schematic of the developed FLOX-combustion system

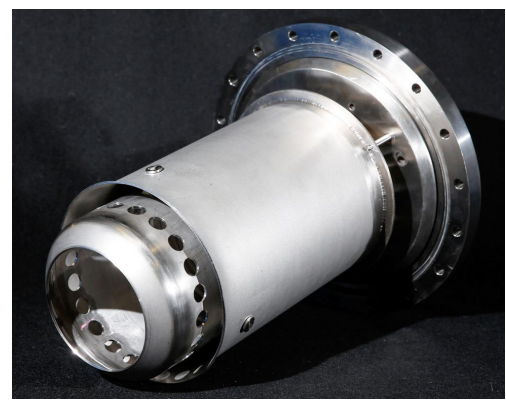

Figure 4: DLR-combustion system for low calorific fuels (picture:DLR/FrankEppler)

In gas turbine combustors the most widespread type of pilot and main stages are swirl-stabilized combustors. One or more swirlers force the air and/or the fuel to rotate around the combustors axis. On the one hand the rotation mixes fuel with air and on the other hand it generates an inner recirculation zone if the swirl is strong enough [20]. The recirculation of hot exhaust gases as well as areas of reduced velocity facilitate flame stabilization. One advantage of swirl combustors is the possibility of small combustion chambers with high power density. For this reason, a swirl combustor is used for the pilot stage of the presented combustion system. The pilot stage is recessed in the center of the combustor. Fuel and air are introduced through a swirler, where they are partially mixed before entering the combustion chamber of the pilot stage. The subsequent main stage contains ten annular air nozzles in which fuel is injected coaxially. The high momentum of the injected jets generates a central recirculation zone, which returns a high amount of exhaust gases to the exit of the jets. This leads to a strong mixing of fuel, air and exhaust gases before the chemical reaction takes place. Additionally, the hot exhaust gases from the pilot stage are entrained by the jets of the main stage. In this way the pilot stage assists the combustion inside the main stage. 


\subsection{Experiments}

Table 2 shows the compositions and the lower heating values of the investigated product gases. These are typical values for product gases from fixed-bed gasifiers, which are widely used in small scale applications. The product gases consist of mainly $\mathrm{H}_{2}, \mathrm{CO}, \mathrm{CO}_{2}, \mathrm{CH}_{4}, \mathrm{H}_{2} \mathrm{O}$ and $\mathrm{N}_{2}$, whereby its lower heating value (LHV) varies between 3.5 and $5.0 \mathrm{MJ} / \mathrm{kg}$ [21. Table 3 shows the operated steady-state load points. With a constant lower heating value of $5.0 \mathrm{MJ} / \mathrm{kg}$ the turbine speed was varied between $80 \%$ and $100 \%$. Due to the limited operating range of each mass flow controller, the product gas composition had to be varied to cover the whole operating range of the MGT. In some operating points the TOT had to be reduced because of the power electronic or to avoid surging of the compressor. At $82.5 \%$ speed the TOT was varied from $645^{\circ} \mathrm{C}$ down to $360^{\circ} \mathrm{C}$. Additionally, three different lower heating values were examined at the same speed with a TOT of $600^{\circ} \mathrm{C}$. Under part load conditions, combustion occurs with high excess of oxygen. Considering it as worst conditions for combustion, $82.5 \%$ was chosen to vary the lower heating value. Furthermore, the power electronic offers a wide range for variation at part load.

Table 2: Product gas (PG) compositions in Vol.-\%, LHV in MJ/kg

\begin{tabular}{ccccccc} 
& $\mathrm{H}_{2}$ & $\mathrm{CO}$ & $\mathrm{NG}$ & $\mathrm{CO}_{2}$ & $\mathrm{~N}_{2}$ & $\mathrm{LHV}$ \\
\hline PG1 & 18 & 22 & 2.25 & 12 & 45.75 & 5.0 \\
PG2 & 15 & 17.6 & 5 & 12 & 50.4 & 5.0 \\
PG3 & 16.8 & 18 & 2.1 & 12 & 51.1 & 4.3 \\
PG4 & 16 & 12 & 2 & 12 & 65.2 & 3.5 \\
PG5 & 17.2 & 15 & 5 & 12 & 50.8 & 5.0
\end{tabular}

Table 3: Steady-state load points

\begin{tabular}{llll} 
Speed $(\%)$ & TOT $\left({ }^{\circ} \mathrm{C}\right)$ & PG & LHV $(\mathrm{MJ} / \mathrm{kg})$ \\
\hline $80-100$ & $\max$. & $1,2,5$ & 5.0 \\
82.5 & $360-645$ & 1,2 & 5.0 \\
82.5 & 600 & $1,3,4$ & $3.5-5.0$ \\
$80-100$ & $\max$. & NG & 48
\end{tabular}

\section{Numerical setup}

At DLR a numerical simulation program was developed to analyze the steady-state performance of the Turbec T100 22 24]. The program is based on models for each MGT component and on extensive experimental data collected at the DLR MGT test rig. Furthermore, the compressor map and the turbine map are embedded in the program. The limits of the power electronic are included and can be optionally turned on by the user. The input parameters are fuel composition and temperature, ambient air temperature, pressure 
and relative humidity, rotational speed and a maximum allowed turbine outlet temperature. Additionally, the recuperator efficiency, heat losses, pressure losses and conversion losses from the generator and the power electronic are considered as well as miscellaneous losses coming from the auxiliary units and other components. The program calculates temperature, pressure, mass flow, gas composition and specific data for each component. It also permits to evaluate the performance of each component and of the complete system for various fuel compositions. In this paper, the program was used to investigate further potentials for optimization of the Turbec T100 with regard to operation with low calorific fuels. By using the obtained experimental data, the program has been validated analog to 24 .

\section{Experimental results}

\subsection{Start-up procedure}

The start-up procedure constitutes a critical maneuver because the MGT must be accelerated rapidly to avoid excitation of its resonant frequencies. As a consequence, the conditions in the combustion chamber change strongly and therefore, the risk of flame extinction is high. Figure 5 illustrates the start-up procedure of the Turbec T100 fired with product gas PG1 from cold conditions. Turbine speed, TOT and electrical power output $\mathrm{P}_{e l}$ are plotted against time. At the beginning, the generator worked as an engine and accelerated the turbine up to $28 \%$ speed. Ignition occurred after a short period of ventilation. At this point, pilot fuel was controlled in closed loop with TOT in order to follow a specified ramp. The turbine accelerated rapidly to $75 \%$ after a TOT of $230^{\circ} \mathrm{C}$ and $35 \%$ turbine speed was reached. This is due to the resonant frequencies lying in this region. During ramp up the main stage was activated, which contributed in delivering the required thermal power. Main fuel was controlled in closed loop with TOT at $75 \%$ turbine speed, and pilot fuel was then controlled based on the pilot map, which was adjusted for product gas operation. The required speed was achieved after 400 seconds. After 1000 seconds the maximum TOT was reached and stabilized. The maximum electrical power output for the given speed was also obtained at this point. Finally, the graph shows smooth curves of speed and TOT. This indicates stable combustion during the start-up procedure. Similar results were observed for PG 2, 3 and 4 . This shows that the FLOXcombustion system provides reliable start-up of the MGT with product gases from fixed-bed gasifiers.

\subsection{Steady state load points}

\subsubsection{MGT performance}

The Turbec T100 has been analyzed by controlling and varying turbine speed at a maximum TOT of $645^{\circ} \mathrm{C}$ in order to reach maximum electrical power output. Due to the limited capacity of the CO-mass 


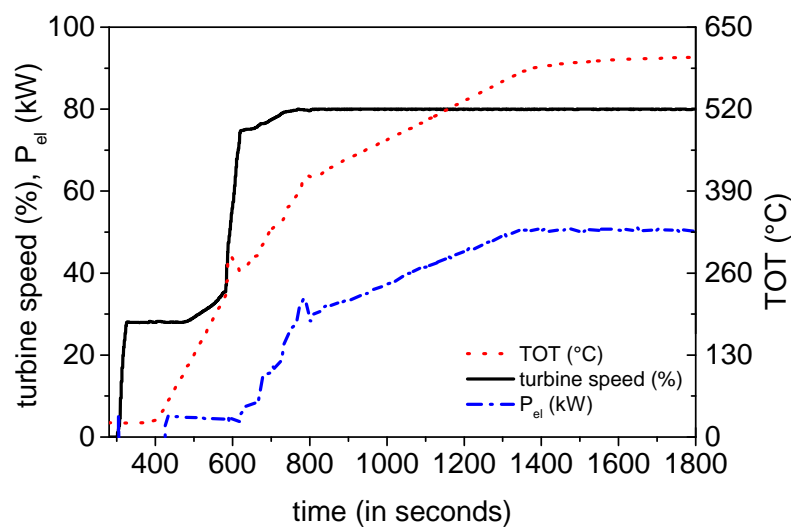

Figure 5: Start-up procedure of the Turbec T100 from cold conditions with a FLOX-combustion system and fired with product gas (PG1)

Table 4: Ambient conditions during the experiments

\begin{tabular}{lccc} 
fuel & $\begin{array}{c}\text { temp. } \\
\left({ }^{\circ} \mathrm{C}\right)\end{array}$ & $\begin{array}{c}\text { rel.humidity } \\
(\%)\end{array}$ & $\begin{array}{c}\text { pressure } \\
(\text { bar })\end{array}$ \\
\hline product gas & $6-7$ & $64-68$ & 0.95 \\
natural gas & $11-14$ & $33-49$ & 0.95
\end{tabular}

flow controller, the product gases PG1, 2 and 5 had to be operated to cover the whole range of turbine speed. Figure 6 presents the electrical power output $\mathrm{P}_{e l}$ and the efficiency $\eta_{e l}$ versus turbine speed. The performance with the original Turbec combustion chamber and natural gas is also shown for comparison. The electrical power output $\mathrm{P}_{e l}$ and the efficiency $\eta_{e l}$ are plotted versus turbine speed. $\mathrm{P}_{e l}$ increased continuously with higher turbine speeds in case of natural gas. In cases with product gases, the electrical power output stagnated at about $100 \mathrm{~kW}_{e l}$ for turbine speeds higher than $92 \%$ and this was due to the TOT, which had to be reduced progressively in order to avoid surging of the compressor. The TOT was also reduced at $80 \%$ turbine speed due to the limitation of minimum voltage of the DC-link. In this case, the TOT is automatically reduced by decreasing the fuel mass flow rate. The maximum TOT was achieved from $82.5 \%$ to $92 \%$ turbine speed. Nevertheless, stable operation of the MGT was observed from $80 \%$ to $100 \%$ turbine speed and the electrical power output ranged from 50 to $100 \mathrm{~kW}_{e l}$. Compared to natural gas, i.e. 40 to $100 \mathrm{~kW}_{e l}$ this range is smaller, but the electrical power output was significantly higher at a fixed speed. The higher power output was partially caused by the ambient conditions, which strongly influence the electrical power output and the electrical efficiency [25, 26]. The ambient conditions during the experiments are listed in table 4 . However, the differences of ambient conditions are too small to explain a $20 \mathrm{~kW}_{e l}$ higher electrical power output with product gases at a turbine speed of $90 \%$.

The electrical efficiency was higher for product gases except for strongly reduced TOT. The electrical 
efficiency was defined as:

$$
\eta_{e l}=\frac{\text { effective power output }}{\text { LHV } * \text { fuel mass flow }}
$$

The energy needed for fuel compression was not considered in both cases because the fuel at the test rig is taken out of bundles. Similar to the power output, the efficiency increased with speed. A maximum $\eta_{e l}=31.5 \%$ was reached with product gases at $92 \%$ turbine speed before it decreased due to the progressive reduction of TOT. The Turbec T100 on the other hand shows high efficiency although it is not optimized for product gas operation.

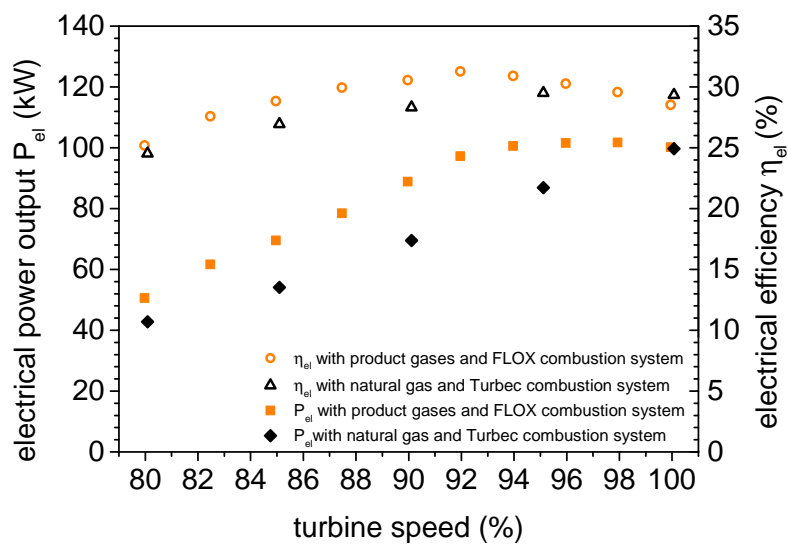

Figure 6: Steady-state operating performance of the Turbec T100 with two different combustion chambers and fuels

For a better understanding of the limitation by compressor surging, figure 7 illustrates the operating map of the compressor, where the total pressure ratio $\Pi$ is plotted against the corrected mass flow $\mathrm{m}_{C}$. In order to keep it independent from the inlet Temperature $\mathrm{T}_{0}$ and the inlet pressure $\mathrm{p}_{0}$, it is defined as 27:

$$
\dot{m}_{C}=\frac{\dot{m}_{1} * \sqrt{T_{0}}}{p_{0}}
$$

Additionally, curves of constant speeds are plotted and corrected with respect to the inlet temperature as follows:

$$
N_{C}=\frac{N}{\sqrt{T_{0}}}
$$

The continuous line represents the surge limit of the compressor separated from the MGT while the dashed line represents the stability limit of the compressor within the MGT. The latter was measured at the test rig of DLR 27] and for that purpose an additional Coriolis mass flow meter was installed between compressor and recuperator. The deviation of both curves shows that at the DLR unit it is not possible to use the 
complete operating range offered by the compressor. The restriction of the operating range could be caused by:

- the modifications of the air piping at the test rig

- the matching of turbine and compressor

- manufacturing tolerances

- deterioration of the compressor

Due to the use of the Coriolis there was an additional pressure drop of $3.5 \%$, which required a higher pressure ratio at the compressor. The flow field at the compressor outlet may have been affected and thus the stability limit. A change is indicated by the operating points obtained in this work, which were measured without Coriolis. Several operating points are located above the stability limit. Before removing the Coriolis, surging occured at $92 \%$ turbine speed which was in accordance to the dashed line. Without the Coriolis, stable operation was observed at this point. Comparing to natural gas, the use of product gases shifted the operating points towards the stability limit. Therefore, operation was limited at higher turbine speeds and as a consequence, the TOT had to be reduced to run the MGT with higher turbine speeds than 92\%. As mentioned above, the influences on the stability limit are manifold. The operating range might be larger with a new unit that doesn't feature the modifications of the piping. Considering that the turbo components of the Turbec T100 are designed and optimized for natural gas, it still offers a wide operating range for the use of product gases. Compressor and turbine need a redesign to increase the operating range.

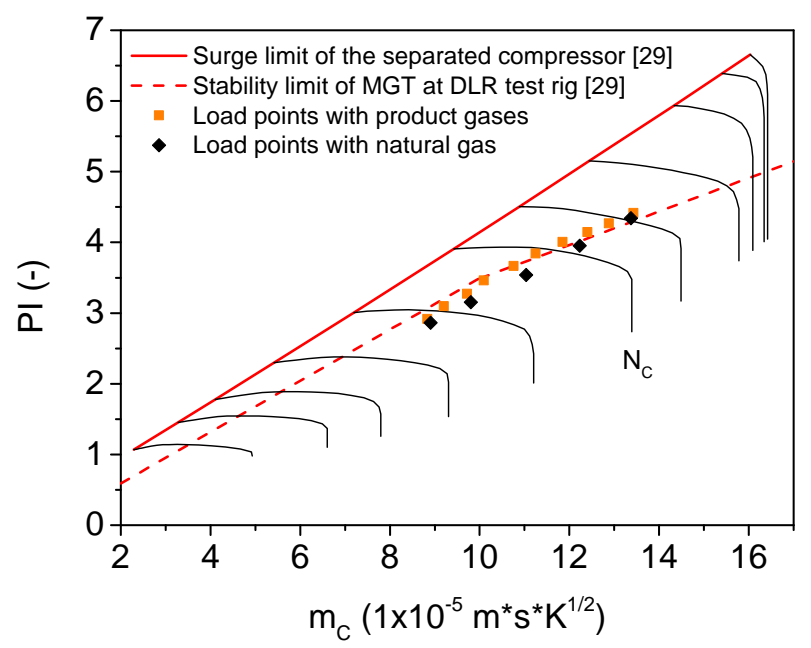

Figure 7: Operated steady-state load points of product gases (LHV $=5 \mathrm{MJ} / \mathrm{kg})$ and natural gas $(\mathrm{LHV}=48 \mathrm{MJ} / \mathrm{kg})$ presented in the compressor map 


\subsubsection{Combustion chamber pressure losses}

The function of the combustion chamber is to mix fuel and air as well as to ensure stable and efficient combustion. To achieve sufficient mixing and flame stabilization, a total pressure loss is inevitable. On the other hand, it is desirable to realize complete and low pollutant combustion with a minimized total pressure loss concerning the electrical efficiency of the MGT. In this work, the total pressure loss from the recuperator outlet 2 (see figure 1) to the turbine inlet 3 was defined as:

$$
\Delta p_{2,3}^{t}=\frac{p_{2}^{t}-p_{3}^{t}}{p_{2}^{t}} * 100[\%]
$$

where $p_{2}^{t}$ is the total pressure at the air-side recuperator outlet measured with a total pressure transducer. The pressure losses of the piping between recuperator and combustion chamber were included. At the inlet f the turbine, the total pressure was calculated from the measured static pressure and the dynamic pressure:

$$
p_{3}^{t}=p_{3}+\frac{1}{2} \rho_{e x} c^{2}
$$

whereby the velocity $c$ can be derived from:

$$
\dot{m}_{3}=\rho_{e x} A c
$$

$\dot{m}_{3}$ is the exhaust gas mass flow, which was calculated from the measured fuel mass flow and from the air mass flow. The latter was obtained via calculating the air number $\lambda$ from exhaust gas analysis as described in the following subsection. $A$ is the cross-section at the turbine inlet and $\rho_{e x}$ is the exhaust gas density, which was calculated from the ideal gas equation:

$$
p_{3}=\rho_{3} R_{e x} T_{3}
$$
The average value from six thermocouples at the combustion chamber outlet has been taken for the temperature $\mathrm{T}_{3}$. For the measured exhaust gas composition, the specific gas constant $R_{e x}$ was calculated. The FLOX-combustion chamber produced a pressure loss of $3.9 \%$. Compared to $5.6 \%$ of the Turbec combustion chamber fired with natural gas, this corresponds to a reduction of about $30 \%$. The latter is a swirl stabilized combustor, which contains two counter-rotating swirlers in the main stage. They provide a high mixing rate of fuel and air as well as a short combustion zone, but its drawback is a high pressure loss. A reduction 
of the pressure loss is beneficial because it leads to a lower pressure ratio at the compressor. Hence, the operating points move away from the stability limit, and the electrical efficiency of the MGT increases.

\subsubsection{Exhaust gas emissions}

Figure 8 presents the exhaust gas emissions of the Turbec T100 operated with the FLOX-combustion chamber and product gases. The emissions of $\mathrm{CO}, \mathrm{NO}_{x}$ and unburnt hydrocarbons (UHC) are plotted versus speed. Error bars are calculated from the standard deviation of the measured data and the propagation of uncertainty. In case of $\mathrm{NO}_{x}$ and UHC the error bars are too small to be visible in the graph. Additionally, the global air number is presented as well as the combustor air inlet temperature (CIT). As the composition of fuel is known, it is possible to calculate the air number via carbon balancing from emission data as follows 28]:

$$
\lambda=\frac{21}{79 * 0.21 * L s t}\left[\frac{\left(C O_{2}^{f}+C O^{f}+C_{x} H_{y}^{f}\right) * N_{2}^{e x}}{C O_{2}^{e x}+C O^{e x}+C H_{4}^{e x}}-N_{2}^{f}\right]
$$

where Lst is the stoichiometric air-to-fuel ratio, superscript $f$ indicates the volumetric concentration in the fuel while $e x$ indicates the concentration in the exhaust gas. Due to the negligible concentration of unburnt hydrocarbons in the exhaust gas, $\mathrm{CH}_{4}$ was chosen to represent total hydrocarbons. The stoichiometric air-to-fuel ratio for a given product gas composition can be calculated by :

$$
L s t=4.762 *\left(l s t_{C O} * x_{C O}+l_{s t} t_{H 2} * x_{H 2}+l s t_{N G} * x_{N G}\right)
$$

here, $x_{i}$ is the molar fraction of component $\mathrm{i}$ and $l s t_{i}$ is the oxygen demand for complete oxidation of i. lst $_{N G}$ has been calculated from the composition of the used natural gas, which was analyzed by gas chromatography. Figure 8 shows a low level of pollutant emissions without strong changes over the whole operating range. Looking more into detail, $\mathrm{CO}$ decreased with increasing turbine speed until a minimum of $13 \mathrm{ppm}$ was reached at $92 \%$. With higher turbine speeds, the CO-concentration increased again to $17 \mathrm{ppm}$. The $\mathrm{NO}_{x}$-emissions showed an opposite behavior. In contrast to $\mathrm{CO}, \mathrm{NO}_{x}$ increased until a maximum of 5 ppm was reached at $92 \%$ turbine speed.

To explain this behavior of $\mathrm{CO}$ - and $\mathrm{NO}_{x}$-emissions, it is necessary to look at the CIT and the air number $\lambda$. Both of these parameters affect the combustion temperature and thus the formation of pollutants. The air number and the CO-emissions showed a minimum of 7.2 and of $15 \mathrm{ppm}$ respectively at $92 \%$ turbine speed. The adiabatic flame temperature decreased with increasing air number. Hence, the adiabatic flame temperature was highest at $92 \%$ turbine speed because of the air number and the high CIT. Therefore, the 


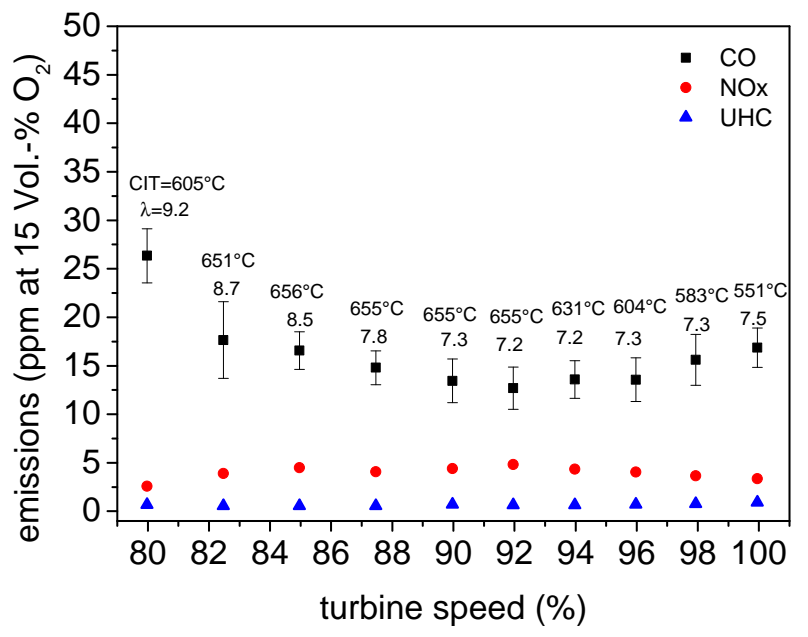

Figure 8: Pollutant emissions of the Turbec T100 operated with a FLOX-combustion system and product gases (LHV $=5$ $\mathrm{MJ} / \mathrm{kg})$

conditions for $\mathrm{CO}$ oxidation were best. Nevertheless, the formation of thermal NO 29] rises with increasing temperature. That is why $\mathrm{NO}_{X}$-emissions are highest at this point. As explained in 4.2.1, the maximum TOT was reached only between $82.5 \%$ and $92 \%$ turbine speed, while for other speeds the TOT had to be reduced. The reduction affected both the CIT and the air number. The CIT depends on TOT because the air is heated up in the recuperator by using the thermal energy of the exhaust gas. If TOT is reduced at a constant speed, the amount of fuel injected into the combustion chamber is reduced respectively. The pressure inside the combustion chamber decreases at the same time and therefore more air is delivered by the compressor. As a result the air number increases if TOT is reduced at a constant turbine speed. Due to higher air number and lower CIT, the combustion temperature falls and consequently $\mathrm{NO}_{x}$ emissions decrease while CO-emissions increase. This behavior has been further analyzed by varying TOT at a fixed turbine speed of $82.5 \%$. In figure 9 pollutant emissions are plotted against TOT and again the air number is calculated for the steady-state load points. A sharp increase of CO-emissions was observed below $500^{\circ} \mathrm{C}$, where the large standard deviation represents the fluctuating behavior. Combustion became progressively incomplete and below $450^{\circ} \mathrm{C}$ the unburnt hydrocarbons increased additionally. Although combustion was poor at $360^{\circ} \mathrm{C}$, the Turbec T100 operated stable. A CO-concentration of $76 \mathrm{ppm}$ was measured at $550^{\circ} \mathrm{C}$. This signifies that even if the maximum TOT is reduced about $100^{\circ} \mathrm{C}$ at part load, the emission limits of the german directive $(80 \mathrm{ppm}) 30$ are met. The overall low level of pollutants over a wide operating range indicate complete and clean combustion. Thus the developed combustion system enables reliable firing of product gases in a MGT. Meeting emission regulations can be achieved even at part load and with partially reduced TOT. 


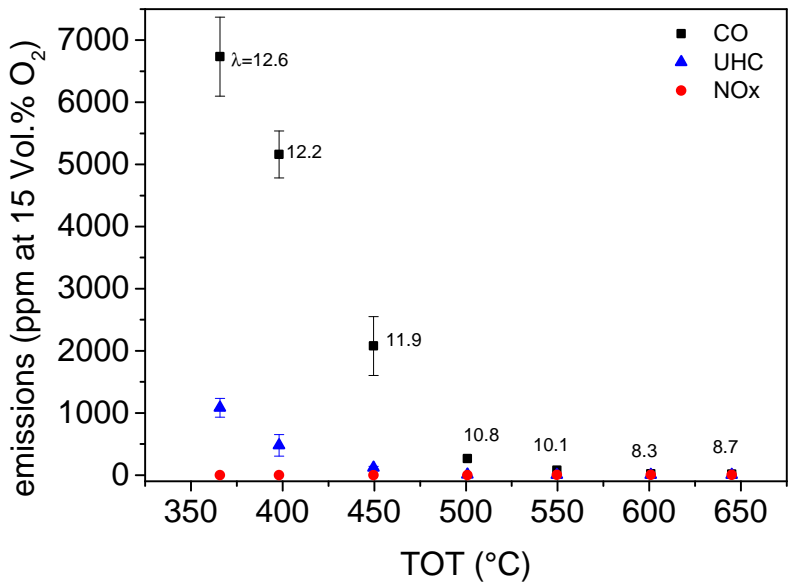

Figure 9: Emission behavior with product gases $(\mathrm{LHV}=5 \mathrm{MJ} / \mathrm{kg})$ and reduced TOT at a constant turbine speed of $82.5 \%$

\subsubsection{Fuel flexibility}

Product gases from biomass gasification feature fluctuations regarding composition and lower heating value. Therefore, it is necessary that combustion systems assure stable combustion for a wide range of typical product gases. The impact of the lower heating value on the MGT perfomance and on pollutant emissions has been examined in this experiment. Table 5 shows the experimental data for three fuel compositions. The turbine speed chosen was $82.5 \%$ because this speed offered the largest range regarding power electronic, stability limit and fuel supply system. The power electronic limited the electrical power output for PG4. A maximum TOT of $600^{\circ} \mathrm{C}$ was achieved and consequently, the three fuel compositions were operated with the same conditions. The results show an increase of $54 \%$ in the fuel mass flow rate from PG1 to PG4 caused by the reduced LHV. The electrical efficiency remained constant because the electrical power output and the thermal power input both increased similarly by $7 \%$. The higher fuel mass flow rate increased the pressure inside the combustion chamber and hence, less air was delivered by the compressor. Its operating points moved towards to the stability limit with decreasing LHV, but they remained inside the stable region. Regarding pollutant emissions, there was no significant change observed. The results demonstrate the stability and fuel-flexibility of the FLOX-combustion chamber, which assured stable and complete combustion. It also shows the increasing limitation of the power electronic with decreasing LHV. The stability limit will additionally restrict operation with decreasing LHV at other speeds. In order to increase the operating range of the Turbec T100 for the use of low calorific fuels, the power electronic and the stability range require optimization. 
Table 5: MGT and pollutant emission data with reduced LHV at a constant turbine speed of $82.5 \%$ and $\mathrm{TOT}=600^{\circ}$

$\begin{array}{lllllll}\mathrm{PG} & \mathrm{P}_{\text {el }} & \eta_{e l} & \dot{m}_{\text {fuel }} & \mathrm{CO} & \mathrm{NO}_{x} & \mathrm{UHC} \\ & \mathrm{kW} & \% & \mathrm{~g} / \mathrm{s} & \mathrm{ppm} & \mathrm{ppm} & \mathrm{ppm} \\ 1 & 57 & 26.8 & 43.3 & 25 & 2 & <1 \\ 3 & 59 & 26.8 & 51.0 & 22 & 1 & <1 \\ 4 & 61 & 26.8 & 66.6 & 30 & <1 & <1\end{array}$

\section{Numerical results}

The operating performance of the MGT fired with product gases has been simulated with a Turbec T100 steady-state simulation tool for two cases. While in the first case the limitation of the power electronic is neglected, this restriction is considered in the second case. In both cases it is assumed that the compressor behaves according to the compressor map without being limited by surging. The results are presented in figure 10 and compared to the experimental results. Electrical power output and electrical efficiency are plotted versus turbine speed analog to figure 6 . The simulation shows good agreement with the experiments from $80 \%$ to $92 \%$ turbine speed. In this operating range, the TOT reached $645^{\circ} \mathrm{C}$ (except at $80 \%$ ). Simulation and experiment differ increasingly at higher turbine speeds because in the experiments the TOT was reduced progressively with higher turbine speed. If the limitation by the power electronic is considered, the TOT is reduced at high loads not because of the stability limit, but due to maximum voltage. Therefore, the reduction is less than in the experiments. The first simulation shows an increase of the electrical power output from $50 \mathrm{~kW}_{e l}$ at $80 \%$ turbine speed to $137 \mathrm{~kW}_{e l}$ at $100 \%$. Hence, the operating range from the Turbec T100 would be about $80 \%$ larger than in the experiments. Compared to the operation with natural gas, it is $50 \%$ larger as well. Without the limitations of compressor surging at the DLR unit and of the power electronic, the efficiency increases continuously with turbine speed. The maximum $\eta_{e l}$ is $33 \%$ and it is reached at $100 \%$ turbine speed. In the second case, the results show a maximum power output of $122 \mathrm{~kW}_{e l}$ with an efficiency of about $31 \%$ at $100 \%$ turbine speed. However, the first simulation identifies a promising potential to optimize the Turbec T100 for the operation with product gases.

\section{Conclusions}

The performance of the micro gas turbine Turbec T100 has been characterized for the use of product gases from biomass gasification in a laboratory test rig. To operate the Turbec T100 with product gases, a new FLOX-combustion system has been successfully developed and integrated. Low pollutant emissions are achieved over the whole operation range, i.e. CO-emissions are less than $30 \mathrm{ppm}$ and $\mathrm{NO}_{x}$ less than $6 \mathrm{ppm}$. Furthermore, no unburnt hydrocarbons have been detected. The FLOX-combustion system enables stable 


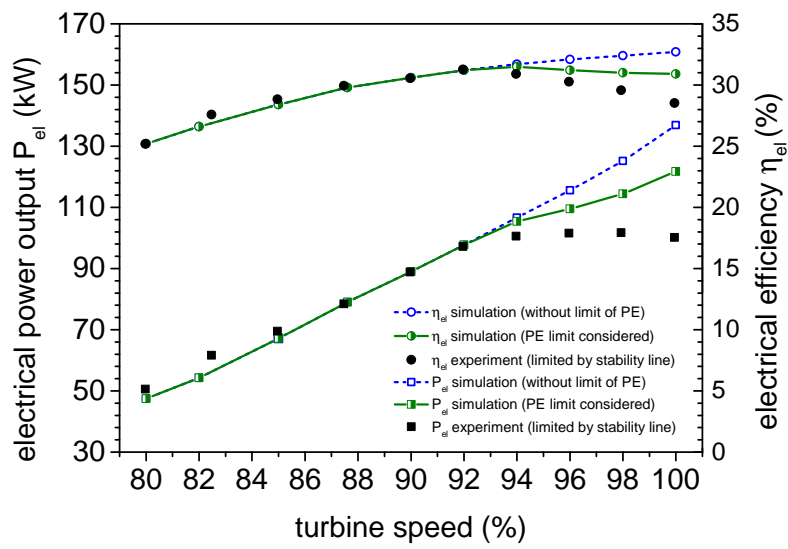

Figure 10: Potential operating range of a Turbec T100 fired with product gases $(\mathrm{LHV}=5 \mathrm{MJ} / \mathrm{kg})$

operation of the Turbec $\mathrm{T} 100$ in the range from 50 to $100 \mathrm{~kW}_{e l}$ as well as reliable starting behavior. The variation of the lower heating value from 3.5 to $5.0 \mathrm{MJ} / \mathrm{kg}$ at a speed of $82.5 \%$ showed stable operation as well while the efficiency remained constant. Comparing the MGT operation with a low calorific fuel to the operation with natural gas at constant turbine speeds, the electrical power output is significantly higher. This is due to a decreased air mass flow rate and a lower mechanical shaft power needed for compression. Hence, the MGT generates more electrical power from the increased residual mechanical shaft power. Especially at higher speeds, operation is limited by the power electronic and by compressor surging. An optimization of the micro gas turbine would offer an operating range of 50 to $137 \mathrm{~kW}_{e l}$, which was indicated by the numerical steady-state simulation. In summary, the results of this work prove the feasibility to operate the Turbec T100 with LCV fuels and additionally, potentials for optimization are identified. The developed combustion system allows meeting emission limits over the whole operating range, i.e. from $80 \%$ to $100 \%$ turbine speed.

This is an important fact as flexible operation is a requested target for future energy production.

\section{Acknowledgements}

The authors wish to thank J. Zanger, M. Stärk, J. Eichhorn and R. Bruhn for their support at the test rig as well as N. Klempp and M. Henke for their help with the numerical simulation. The German Federal Ministry for Economic Affairs and Energy is gratefully acknowledged for funding the project (grant number 03KB047A).

\section{References}

[1] Pilavachi PA. Power generation with gas turbine systems and combined heat and power. Applied Thermal Engineering 2000;20:1421-9. 
[2] Gupta K, Rehman A, Sarviya R. Bio-fuels for the gas turbine: A review. Renewable and Sustainable Energy Reviews 2010;14:2946-55

[3] Nikpey H, Assadi M, Breuhaus P, Mørkved P. Experimental evaluation and ann modeling of a recuperative micro gas turbine burning mixtures of natural gas and biogas. Applied Energy 2014;117:30-41.

[4] D'Alessandro B, Testarmata F, Laranci P, Fantozzi F. Experimental and cfd evaluation of the part load performance of a micro gas turbine fuelled with ch4-n2 mixtures. In: Proceedings of ASME Turbo Expo 2012; June 11-15, 2012, Copenhagen, Denmark. GT2012-69790; 2012,.

[5] Kataoka T, Nakajima T, Nakagawa T, Hamano N. Combustion characteristics of methane-co2 mixture and a microturbine cogeneration system utilized sewage digester gas. In: Proceedings of GT2007 ASME Turbo Expo 2007: Power for Land, Sea and Air May 14-17, 2007, Montreal, Canada. 2007,.

[6] Prussi M, Chiaramonti D, Riccio G, Martelli F. Evaluation of a micro gas turbine fed by blends of biomass producer gas and natural gas. GT2008-50236; ASME; 2008,.

[7] Bohn D, Lepers J. Effects of biogas combustion on the operation characteristics and pollutant emissions of a micro gas turbine. In: Proceedings of ASME Turbo Expo 2003 Power for Land, Sea, and Air June 1619, 2003, Atlanta, Georgia, USA. GT2003-38767; 2003,.

[8] Wünning J, Wünning J. Flameless oxidation to reduce thermal no-formation. Progress in Energy and Combustion Science $1997 ; 23(1): 81-94$

[9] Cavaliere A, Joannon M. Mild combustion. Progress in Energy and Combustion Science 2004;30(4):329 -66.

[10] Arghode V, Gupta AK. Effect of flow field for colorless distributed combustion (cdc) for gas turbine combustion. Applied Energy 2010;87:1631-40.

[11] Tsuji H, Gupta A, Hasegawa T, Katsuki M, Kishimoto K, Morita M. High Temperature Air Combustion - From Energy Conservation to Pollution Reduction. Florida: CRC Press; 2003.

[12] Lückerath R, Meier W, Aigner M. Flox combustion at high pressure with different fuel compositions. In: ASME Turbo Expo 2007: Power for Land, Sea and Air, May 14-17, 2007, Montreal, Canada. 2007,GT2007-27337.

[13] Lückerath R, Schütz H, Noll B, Aigner M. Experimental investigation on flox-combustion at high pressure. In: DLR , editor. Flameless Combustion Workshop, Lund, Sweden. 2005,.

[14] Schütz H, Lückerath R, Kretschmer T, Noll B, Aigner M. Analysis of the pollutant formation in the flox combustion. In: Proceedings of ASME Turbo Expo 2006: Power for Land, Sea and Air, May 8-11, 2006, Barcelona, Spain. 2006,.

[15] Flamme M. New combustion systems for gas turbines (ngt). Applied Thermal Engineering 2004;24:1551-9.

[16] Zanger J, Widenhorn A, Monz T, Aigner M. Experimental characterisation of a jet-stabilised micro gas turbine combustor under atmospheric conditions. VDI, 25th German Flame Day Combustion and Furnaces 2011;2119:259-64.

[17] Danon B, de Jong W, Roekaerts DJEM. Experimental and numerical investigation of a flox combustor firing low calorific value gases. Combustion Science and Technology 2010;182:9:1261-78.

[18] Zanger J, Monz T, Aigner M. Experimental investigation of the combustion characteristics of a double-staged flox-based combustor on an atmospheric and a micro gas turbine test rig. In: Proceedings of ASME Turbo Expo 2015: Turbine Technical Conference and Exposition,GT2015-42313, June 15-19, 2015, Montreal, Canada. 2015,.

[19] Hohloch M, Widenhorn A, Lebküchner D, Panne T, Aigner M. Micro gas turbine test rig for hybrid power plant application. In: 2008 ATE, editor. ASME Paper No. GT2008-50443. 2008, p. GT2008-50443.

[20] Lilley D. Swirl flows in combustion: A review. AIAA Journal 1977;15:1063-78. 
[21] Kaltschmitt M. Energie aus Biomasse; chap. 11 Vergasung. ISBN 978-3-540-85094-6; 2nd ed.; Springer-Verlag; 2009, p. $600-28$.

[22] Panne T, Widenhorn A, Boyde J, Matha D, Abel V, Aigner M. Thermodynamic process analyses of sofc/gt hybrid systems. In: AIAA, editor. AIAA Paper No. 2007-4833. 2007,.

[23] Henke M, Monz T, Aigner M. Inverted brayton cycle with exhaust gas recirculation - a numerical investigation. Journal of Engineering for Gas Turbines and Power 2013;135(9):091203-1 .

[24] Henke M, Klempp N, Hohloch M, Monz T, Aigner M. Validation of a t100 micro gas turbine steady-state simulation tool. In: Proceedings of ASME Turbo Expo 2015: Turbine Technical Conference and Exposition,GT2015-42090, June 15-19, 2015, Montreal, Canada. 2015,

[25] TurbecAB . D12451, technical description 2002;(17/06/02).

[26] Renzi M, Caresana F, Pelagalli L, Comodi G. Enhancing micro gas turbine performance through fogging technique: Experimental analysis. Applied Energy 2014;135:165-73.

[27] Zanger J, Widenhorn A, Aigner M. Experimental investigations of pressure losses on the performance of a micro gas turbine system. Journal of Engineering for Gas Turbines and Power 2011;133(8):082302.

[28] Cerbe G. Grundlagen der Gastechnik; chap. 3 Verbrennung der Gase. ISBN: 3-446-17049-9; 4th ed.; Carl Hanser Verlag; 1992 , p. $82-7$.

[29] Warnatz J, Maas U, Dibble RW. Combustion; chap. Formation of Nitric Oxides. ISBN 978-3-540-45363-5; 4th ed.; 2006, p. 259-62. Ch.17.

[30] Federal Ministry for Environment, Building, Nature Conservation and Nuclear Safety . First general administrative regulation pertaining the federal immission control act (technical instructions on air quality control - ta luft). 2002. 